\title{
Methodical Approach to Evaluation of Efficiency of Transformation of Business Processes on Engineering Enterprises in the Context of Ensuring Security
}

\author{
Volodymyr Bazyliuk $^{1 *}$, Oleksandr Molnar², Nataliya Kyrlyk², Roksolana Vynnychuk ${ }^{3}$, Roman Zavadyak \\ ${ }^{1}$ Department of Media Communications and Entrepreneurship, Ukrainian Academy of Printing, Lviv 79020, Ukraine \\ ${ }^{2}$ Department of Economic Theory, State Higher Educational Institution "Uzhgorod National University", Uzhgorod 88000, \\ Ukraine \\ ${ }^{3}$ Department of Human Resource Management and Administration, Lviv Polytechnic National University, Lviv 79000, \\ Ukraine \\ ${ }^{4}$ Department of Economics and Entrepreneurship, State Higher Educational Institution "Uzhgorod National University", \\ Uzhgorod 88000, Ukraine
}

Corresponding Author Email: bazyliukvolodymyr@gmail.com

https://doi.org/10.18280/ijsse.110510

Received: 11 June 2021

Accepted: 26 September 2021

\section{Keywords:}

business process, rating, efficiency, engineering enterprises, transformation, security

\begin{abstract}
The main purpose of the study is the formation the methodological approach to assessing the options for transforming of the main business process in the context of ensuring security. The study is based on the assessment results of several of leading engineering enterprises. The methodology of estimation of efficiency of carrying out transformation of the basic business processes of the enterprises, based on the theory of fuzzy sets, is a convenient means of carrying out multicriteria evaluation, comparative analysis from the point of view of integrated criterion and obtaining orderly priority of business processes on their efficiency. The study of the process of transformation of a business process for the production and sale of product enterprises was conducted and a methodology for assessing its effectiveness based on the use of the mathematical apparatus of the theory of fuzzy sets was formed and allows us to formalize and evaluate the effectiveness of the implementation of each of the options for the business process. Methodology for assessing the effectiveness of the transformation of the main business processes at the enterprises can be used in enterprises of various profiles after the necessary analysis and optimization. The study conducted a comprehensive assessment of the effectiveness of the transformation of the main business processes at the enterprises using as example engineering enterprises in the context of ensuring security.
\end{abstract}

\section{INTRODUCTION}

One of the effective ways of adapting to the institutional changes and new challenges of our time is the processes of modernization of domestic industry, in the context of transforming outdated business processes, taking into account new security challenges, which is understood as: firstly, the long process of the industrial revolution, under the influence of which a small number of highly developed states in technical terms have formed; secondly, constant attempts to catch up with the most progressive countries in development; thirdly, these are the efforts that are carried out by developed countries in order to further intensify their development through the innovation and reform, not only in production, but also in the economic and social spheres.

So, the transformation belongs to the third type of the above processes of modernization, in the context of transforming outdated business processes, taking into account new security challenges and, obviously, is due to the institutional nature. It should be noted that with this definition of transformation, they can only be effectively carried out in industrialized and urbanized societies characterized by a sufficient level of development of political and market institutions. Confirmation of this assumption is the opinion that "transformation is a transition from a dictatorship or an authoritarian system to democracy, from a planned or command economy to a market economy" [1].

Another researcher, Huntington [2], wrote: "modernization is an irreversible process ... by making contact with Western countries, third world countries cannot resist modernization impulses". The subject of study of modernization theory is the complex processes of transformation of the traditional economic system into the modern, and the object is the driving forces of this transition.

Attention should be paid to the peculiarities of the institutional-evolutionary concept, in which special attention is paid to the problem of innovative transformations of the real sector of the economy due to changes in the complexes of technologically connected industries formed in accordance with one or another technological structure. The position of the institutional evolutionary concept lies in the need to form a new technological structure as a result of the full use of technological capabilities and reduce production efficiency in the sectors of the traditional technological structure. This leads to a reorientation of capital from the traditional activities of engineering enterprises to the development of innovations and the development of new areas, which, in turn, causes systemic crises of traditional directions. 
In the modern economic realities of managing, associated with a significant increase in competition in all segments of the engineering market, there is a need to transform the engineering enterprises on the basis of not only technical development plans, but also taking into account changes in the basic business processes.

Thus, the specificity of engineering activities requires a process approach to transformation in the context of ensuring security. Despite the diversity of technologies and types of products, namely, the process approach will be able to provide high-quality identification of the main business processes of engineering enterprises, their analysis and develop an effective model for transforming activities to change.

There are a number of methods for assessing the effectiveness of business processes, which are widely used in world practice. Among them, in our opinion, it is necessary to highlight the following: EVA (Economic value added) methods of cost analysis of business processes ABC (Activitybased costing), Tableau of bord methodology and a balanced scorecard BSC (Balanced Scorecard).

The methodology used for assessing the business process is KPI (Key Performance Indicator), which consists of a set of indicators that help determine the effectiveness of a business process or the degree to which it has achieved certain goals. The ranking of business processes according to this methodology is based on the lean production approach, and the efficiency of business processes itself is assessed according to four criteria:

- the degree of completeness of customer service (the speed of the business process, the content of work on its implementation, etc.);

- business process performance;

- business process costs;

- the quality of the business process.

\section{LITERATURE REVIEW}

Currently, there are a significant number of methods for assessing the effectiveness of the implementation of business processes that are widely used in the world. It is advisable to include the following:

- EVA (Economic value added);

- methodology Tableau of bord;

- balanced scorecard BSC (Balanced Scorecard);

- methods of cost analysis of business processes $\mathrm{ABC}$ (Activity-based costing).

It is important to describe the characteristics of each of the above methods. The EVA methodology is based on the assertion that all business processes have two components the first one adds value to the product, and the second one that does not increase its consumer value [3]. Obviously, for most enterprises, it is precisely ensuring added value by the implementation of the business process that is the main motive for its implementation. This approach involves the assessment of the implementation of the business process, creates added value, using an aggregate indicator (the ratio of market value and actual cost of production). However, in this case, the methodology presented is appropriate in the process of assessing the implementation of only the main business processes and development processes. The use of the presented approach to the assessment of enterprises supporting business processes is impossible, since they alone do not create added value.
Another common approach to assessing the implementation of business processes is the Tableau of bord technique. This is one of the most famous methods for managing the efficiency of business processes of complex socio-economic systems, based on the approach to their decomposition based on the formation of a hierarchical tree of indicators [4].

The positive aspects of the approach include the possibility of constructing a tree of target and functional indicators in such a way that, at the upper levels, the vast majority of the targets are used, and at the middle and lower levels - functional

The main advantages of this technique are the ability to form a tree of indicators of target and functional indicators. So, at the upper levels of the tree, targets are mainly used, and at the lower and middle levels - functional. However, the methodology presented has a number of drawbacks, the main of which is the difficulty of maintaining equilibrium in the system of indicators.

A widely used methodology for assessing the implementation of business processes is the method of cost analysis of $\mathrm{ABC}$ processes. This approach is based on the identification and calculation of costs resulting from the implementation of the business process $[5,6]$. The advantage of the ABC method is the ability to evaluate the effectiveness of resources used as a result of the implementation of the business process. In addition, it can be used for a comprehensive assessment, both in terms of qualitative and quantitative indicators. However, the main drawback of this approach is the difficulty of collecting information about expenses and profits for each division of the enterprise in cases where the business process is implemented by several structural divisions.

Another widely used technique, BSC, can be a definite solution to the problem described above related to $\mathrm{ABC}$, the advantage of which compared with others is the ability to analyse the company's activities in four areas:

- financial;

- client;

- internal processes (the effectiveness of key processes);

- personnel (training and development).

However, there are certain difficulties in applying the presented approach to assess the effectiveness of the business processes of engineering enterprises. Initially, this was caused by difficulties in assessing the direction of client performance. Since a large number of engineering enterprises implement a business process for the production and sale of product labeling, in conditions where consumers of these products are usually entities of the processing industries, the relationship between manufacturers and consumers of labels is mostly long-term. Under such conditions, a client's assessment will be based on an analysis of a small number of label consumers, and will lead to difficulties in identifying low-efficiency business processes.

Another methodology for assessing the effectiveness of the implementation of business processes, based on a study of key performance indicators, is KPI (Key Performance Indicator). It consists of a list of indicators that evaluate the effectiveness and degree of achievement of goals by a business process. The structure of the KPI system is determined depending on the strategy of the organization. It is important that KPIs are not developed for the organization as a whole, but for each goal separately. With the help of the selection of KPIs, it is possible to balance the ratio of financial and non-financial, strategic and tactical goals.

You can use the following methods to implement KPIs: 
- instrumental (creating a base for any special solutions);

- conceptual (forming a vision of a common goal among the employees of the organization, influencing the way of thinking of each individual member of the team, changing the behavior of employees in the direction necessary for the organization, creating a strong corporate culture);

- symbolic (possible only if the organization has formed goals, made a decision, and uses the system of key performance indicators only to ensure the implementation of the chosen strategy).

Most scientists note that often organizations use the wrong parameters for their activities, they mistakenly consider many of the indicators to be KPIs. This is because there are three types of organizational performance indicators:

- key performance indicators;

- production indicators;

- key performance indicators.

The benefits of KPIs are as follows:

- allocation of the share of the implementation of the organizational strategy;

- holistic perception of all the main indicators of the organization's performance within the framework of the KPI system;

- faster tracking of the implementation of tactical and strategic goals of the organization;

- the non-financial nature of these indicators (since the organization is often overloaded with figures and indicators expressed in monetary terms or ratios).

The disadvantages of KPIs are that the interpretation of the results of the performance assessment is not always correct. However, you can try to avoid incorrect interpretation if, at the very beginning, when developing the system, you carefully form the criteria by which the KPI will be assessed in the future.

The ranking of business processes using this technique is carried out using the Lean production approach [7], and the assessment of the effectiveness of the implementation of business processes is based on the following criteria:

- the degree of completeness of customer service (speed of the business process, the content of work on its implementation, etc.);

- costs of the business process;

- efficiency of the business process;

- the quality of the business process [8]

It will also be important to note that today in this scientific field the processes of searching for innovative solutions dominate in the process of improving the general assessment methodology. Important robots in this industry should be considered the work of Nam et al. [9], Stark [10], Shtangret et al. [11], Khalina et al. [12] and Marrella et al. [13].

In our opinion, each of the business processes in the context of ensuring security requires the formation of a special and characteristic criteria system only, and the completeness of the analysis will depend on the type of business process: core, management, or providing. We believe that the system of indicators for assessing the effectiveness of the transformation of both the main business process and its lower levels of the hierarchy should be complete. However, despite the specifics of the assessment of each of the considered business processes, the criteria of effectiveness and efficiency.

This assumption is confirmed by the requirements of the ISO 9001 standard, which provides certification requirements for a quality management system, necessitates the system to achieve maximum performance for each of the ongoing business processes, and the ISO 9004 standard contains recommendations for optimizing the quality management system and increasing the efficiency of the organization's business processes in combination with ensuring their effectiveness.

A generalization of existing methods, which have found wide application in practice, allows us to offer our own vision of indicators for conducting such an assessment, which would later form the basis of our methodological approach based on the application of the theory of fuzzy sets, as a modern tool for solving problems of evaluating the effectiveness of business processes which is an effective tool for solving issues of evaluating the effectiveness of business processes of engineering enterprises in the context of ensuring security.

The advantages of using the theory of fuzzy sets: the ability to include qualitative variables in the analysis and operate with fuzzy input data and linguistic criteria; fast modeling of complex dynamic systems and their comparison with a given degree of accuracy, etc.

\section{METHODOLOGY}

In the developed approach for assessing the effectiveness of the implementation of a business process the important aspect are the evaluation methods and algorithms for calculating the effectiveness of implementation and transformation of processes, characterized by a significant level of uncertainty.

The uncertainty conditions for the assessment method and the algorithm for calculating the effectiveness of the implementation and transformation of processes for the manufacture of engineering products using various printing methods take place when it is known what environmental conditions will come or have already come. For each action it is known that it leads to some specific result. At the same time, for one goal, decisions are unambiguous, and for many goals, one should distinguish between neutral, complementary (complementary) and competing goals.

An effective tool in the study of the development of complex socio-economic systems with a high degree of uncertainty is the theory of fuzzy sets. In conditions of high dynamism of the external environment, the use of the theory of fuzzy sets makes it possible to solve complex economic problems. Therefore, we consider it appropriate to use the theory of fuzzy sets to formulate an approach to assess the effectiveness of the implementation of business processes of engineering enterprises in the context of ensuring security.

Here are the main provisions of the theory of fuzzy sets for the formation of an approach to assessing the effectiveness of the implementation of business processes. Suppose that $\mathrm{K}$ is the basic collection to which objects of a certain class belong, and $P$ is a subset of the collection $K$ to which sets of pairs belong (1):

$$
P=\left\{\mu_{c}(x) / x\right\}, \text { where } x \in K, \mu_{c}(x) \in[0 ; 1] .
$$

$\mu_{c}(x)$ - this is the membership function of the fuzzy set $P$, which for each value $x \in K$ includes some values in the interval $[0 ; 1]$ are called the degree of belonging of a certain element in a fuzzy set $P$. Assume that the set $P$ does not include elements $\left\{\mu_{c}(x) / x\right\}$, for them $\mu_{c}(x)=0$. The "/" symbol indicates the affiliation of each element after it [14].

The degree to which $\mu_{c}(x)$ elements $x$ belong to a fuzzy set $P$ is treated as a subjective measure of how much an element 
$x \in V$ corresponds to a concept that is formalized by a fuzzy set $P$. The membership functions of the same set can be different due to defined by different people or by one person, depending on the purpose constructing a fuzzy set, a problem to be solved, construction methods and the like. In decisionmaking models for using information formalized on the basis of the theory of fuzzy sets, the necessary procedures for constructing the corresponding membership functions. Among the methods for constructing membership functions, a special place is occupied by methods based on expert estimates. Most often used among them are methods when the expert directly sets the rules for determining the membership function $\mu_{c}(x)$ that characterizes the concept of $R$.

We propose an approach to applying the theory of fuzzy sets to formalize an integrated assessment of the effectiveness of business processes of engineering enterprises. To do this, we have described the mathematical formulation of the problem - the creation of an integrated methodology for assessing the effectiveness of the implementation of a business process with a certain set of options.

Suppose there is a certain number of business process implementation options $K=\left\{v_{i}\right\}, i=\overline{1, n}$ and a certain list of evaluation criteria $A=\left\{A_{j}\right\}, j=\overline{1, m}$. So, the evaluation criteria are local indicators (quantitative and qualitative) of the effectiveness of the business process, which are inherent in some concepts, and the assessment of alternatives is the degree of compliance with this concept. The proposed system for assessing the effectiveness of the main business process for the manufacture of engineering products consists of two groups of indicators: quantitative - size, which can be measured directly and qualitative - their measurement in most cases is carried out indirectly on the basis of expert assessments, increases their subjectivity.

Thus, within the quantitative indicators of the efficiency of using the business process, taking into account the peculiarities of publishing and printing activities in the region, it is proposed to use the following groups of indicators:

- cost - the indicators characterize the amount of resources used by the business process, and the profit received after the sale of products manufactured using the implementation of the process. The indicators of this group are considered important, since they directly characterize the efficiency of business processes in value terms. Thus, in order to form an effective system for assessing a business process, we consider it appropriate to combine a number of indicators. So, the cost assessment of a business process can be carried out on the basis of an indicator, which is calculated through the ratio of the volume of production using a certain business process to the cost of resources incurred for its implementation;

- technical - includes indicators characterizing equipment and technologies used in the implementation of a business process. Technical parameters serve as the basis for the formation of a group of specific technical indicators for evaluating a business process (for example, such as production per employee, the degree of process automation and the cost of using new technologies, etc.). It should be noted that, due to technological features, different industries can form different groups of indicators that meet the requirements of the current analysis of the effectiveness of a particular business process. So, despite the indicated promising directions for transforming the business process for the production of engineering products, it was found that under the influence of changes in the institutional environment, significant interest in transformations lies in the technological plane (the use of new types of printing - digital, electrographic and a significant impact on the development of information technologies). Despite this, we believe that since the business process for the production of engineering products is being evaluated, it is necessary to apply an indicator that would combine the sale of publishing and printing products and the costs of introducing new technologies. So, this indicator is proposed to be calculated from the ratio of products sold (both produced using new technologies and equipment, and sold using electronic commerce) to the costs of introducing new equipment and technologies;

- temporary - show the efficiency of using time in a business process, allow you to identify unnecessary process functions and determine the amount of downtime. In order to analyze the proposed group of indicators, it is necessary to form a time tracking system: the implementation of each business process must be regulated and comparable to the established norms. It should be noted that for the business process for the manufacture of engineering products there is a system of norms and standards for the regulation of this process, and a significant reserve for increasing the efficiency of production of products is the reduction, based on the use of innovative approaches, of the costs of working time (including unproductive ones) and the reduction of the cycle time. for the production and sale of products. So, an indicator that could fully assess the efficiency of a business process from the point of view of time is the cycle time for the production of engineering products.

Evaluation of possible options for implementing a business process for each $i$-criterion is determined by a fuzzy set $A_{i}(2)$ :

$$
A_{i}=\left\{\mu_{T_{i}}\left(K_{1}\right) / K_{1}, \mu_{T_{i}}\left(K_{2}\right) / K_{2}, \ldots, \mu_{T_{i}}\left(K_{n}\right) / K_{n}\right\} .
$$

Under these conditions, the coagulation rule looks like this (3)

$$
\mu_{e}\left(K_{i}\right)=\min _{j} \mu_{T_{j}}\left(K_{i}\right), i=\overline{1, n}, j=\overline{1, m}
$$

where, $E I$ is the intersection of fuzzy sets for all criteria that satisfy the condition for choosing the best option and is calculated by the formula (4):

$$
E=A_{1} \cap A_{2} \cap \ldots \cap A_{m}
$$

The best option is $\mathrm{K}^{*}$ implementation of the business process, which will have the maximum value of the membership function (5):

$$
\mu_{E}\left(K^{*}\right)=\max _{i} \mu_{E}\left(K_{i}\right), i=\overline{1, n}
$$

The previous reasoning was based on the fact that all criteria are of equal importance, but basically this is not so. As a rule, their contribution to ensuring the efficiency of the process is different. Let $\alpha_{1}, \alpha_{1}, \ldots \alpha_{m}$ be integral numbers characterizing the relative importance of the criteria $A_{1}, A_{2} \ldots A_{m}$, moreover $\sum_{j=1}^{m} \alpha_{j}=1$. If it is more convenient to evaluate the importance of the criteria by numbers exceeding one, then you can first use the quantitative scale that is convenient (for example, in the range from 0 to 10 ), and then calculate the fate of each number in total amount. That is, if initially importance is estimated in numbers $\tilde{\alpha}_{i}(i=\overline{1, m})$ from the interval $[0, \mathrm{a}]$, then (6): 


$$
\alpha_{i}=\frac{\tilde{\alpha}_{i}}{\sum_{j=1}^{m} \tilde{\alpha}_{j}}
$$

To order options, a fuzzy $A$ set is defined in the form of a convex combination of fuzzy sets $\widetilde{\widetilde{A}}_{j}(j=\overline{1, m})$ with a membership function (7):

$$
\mu_{\widetilde{T}}\left(K_{i}\right)=\sum_{j=1}^{m} \alpha_{j} \mu_{T_{j}}\left(K_{i}\right), i=\overline{1, n}
$$

Thus, the implementation of the proposed approach allows us to formalize and numerically evaluate the effectiveness of each of the options for the business process of engineering enterprises in the context of ensuring security, has transformed.

\section{RESULTS OF RESEARCH AND DISCUSSION}

In order to conduct a full assessment in accordance with the proposed areas, a list of indicators for assessing the transformation of the business process of engineering enterprises was formed, namely: the ratio of the volume of production using a specific business process to the cost of resources incurred for its implementation (A1) coefficient the ratio of products sold (both manufactured using new technologies and equipment, and sold using electronic commerce) to implementation costs a marketing techniques and technologies (A2) the duration of the cycle of production and sale of engineering products (A3) quality process (A4) adaptive process (A5). However, we believe that this list of indicators is incomplete for an effective assessment, since it does not take into account common indicators that would take into account the degree of profitability of the business process and the human factor. Other scholars, such as A. Welch and G.
Short, adhere to the same opinion, who note that "... there are several coefficients or percentages that are commonly used because they are suitable for many cases" [15]. So, we consider it expedient, in addition to the above indicators, to attract the profitability coefficient of the business process, calculated as the ratio of net profit received as a result of the implementation of the process, to the total costs of its implementation (A6) and the indicator of the productivity of the process - the ratio realized by the process products in the number of personnel necessary for the normal course of the business process (A7).

For the purpose of practical testing, we will consider the task of choosing the best option for a business process for the production and sale of product labeling by engineering enterprises, that is, the most effective business process of existing ones. The choice of the basis of this business process is justified by the fact that the label remains one of the few types of engineering products that will provide high profitability and further development of engineering enterprises. Five options for the implementation of this business process are identified, based on the use of various methods. The orientation is precisely on the manufacture, and not on the sale, the etiquette of the product is determined by the specifics of its sale, which consists mainly in direct contracts with customers, which makes the sales process almost invariable.

The existing matrix of indicators and their corresponding expert assessments. The experts were 12 representatives of engineering enterprises of Ukraine (manufacturers of engineering products), who were asked to evaluate each of the criteria (A) for each of the options. To make a decision, first of all, it is necessary that all data characterizing the heterogeneous parameters become comparable and quantitative. To do this, for each version of the business process for the value of each parameter with the help of experts, a numerical rating is set out that characterizes how effective the corresponding value is (Table 1).

Table 1. Indicators for evaluating options for implementing a business process for the production of engineering products

\begin{tabular}{cccccc}
\hline \multirow{2}{*}{ Indicators } & \multicolumn{5}{c}{ Business Process Implementation Options } \\
& I (offset) & II (flexo-graphic) & III (electro-graphic) & IV (digital) & V (type-offset) \\
\hline A1 & 2,2 & 2 & 1,8 & 2 & 2,3 \\
A2 & 0,7 & 0,8 & 0,9 & 0,7 & 0,8 \\
A3 & 18 & 15 & 15 & 14 & 16 \\
A4 & above average & above average & high & very high & High \\
A5 & high & high & above average & high & above average \\
A6 & 0,25 & 0,35 & 0,4 & 0,35 & 0,3 \\
A7 & 72 & 78 & 75 & 74 & 75 \\
\hline
\end{tabular}

To assess the consistency of expert opinions, the coefficient of concordance (consistency) is calculated, which can take values in the range from zero to one (8):

$$
W=\frac{12 \sum_{j=1}^{m}\left(S_{j}-\bar{S}\right)^{2}}{n^{2} \times\left(m^{3}-m\right)}
$$

If the coefficient of concordance (W) is equal to zero, then this indicates an absolute inconsistency of the opinions of experts. The value of $\mathrm{W}$, equal to one, indicates a complete coincidence of the opinions of experts.

The consensus of opinions of experts is considered acceptable if the value of the coefficient of concordance (W) is greater than or equal to 0.6 .

Improving the consistency of expert opinions at $\mathrm{W}<0.6$ can be achieved as a result of repeated rounds of expert interviews or by finding and rejecting "jumping out experts".

Table 2. Verbal-numerical scale

\begin{tabular}{cc}
\hline Name of graduation & Numeric intervals \\
\hline very high & $1.0-0.8$ \\
high & $0.8-0.63$ \\
average & $0.63-0.37$ \\
week & $0.37 .-0.2$ \\
very low & $0.2-0.0$ \\
\hline
\end{tabular}

Moreover, the quantitative values for the qualitative 
indicators A4 and A5 are determined on the basis of the Harrington verbal-numerical scale [5], which includes the name of the gradation and the corresponding ranges of numerical values that are meaningfully described (Table 2).

As a result, the following expert numerical estimates of the available criteria were obtained (Table 3 ).

Table 3. Numerical evaluation of the criteria

\begin{tabular}{|c|c|c|c|c|c|c|c|c|c|c|}
\hline \multirow{2}{*}{ Indicators } & \multicolumn{2}{|c|}{ I (offset) } & \multicolumn{2}{|c|}{ II (flexo-graphic) } & \multicolumn{2}{|c|}{ III (electro-graphic) } & \multicolumn{2}{|c|}{ IV (digital) } & \multicolumn{2}{|c|}{ V (type-offset) } \\
\hline & Value & Rating & Value & Rating & Value & Rating & Value & Rating & Value & Rating \\
\hline A1 & 2.2 & 0.75 & 2 & 0.43 & 1.8 & 0.24 & 2 & 0.41 & 2.3 & 0.83 \\
\hline A2 & 0.7 & 0.74 & 0.8 & 0.83 & 0.9 & 0.97 & 0.7 & 0.70 & 0.8 & 0.85 \\
\hline A3 & 18 & 0.41 & 15 & 0.58 & 15 & 0.63 & 14 & 0.80 & 16 & 0.66 \\
\hline A4 & $\begin{array}{l}\text { above } \\
\text { average }\end{array}$ & 0.57 & $\begin{array}{l}\text { above } \\
\text { average }\end{array}$ & 0.59 & high & 0.78 & $\begin{array}{l}\text { very } \\
\text { high }\end{array}$ & 0.93 & high & 0.75 \\
\hline A5 & High & 0.69 & high & 0.74 & $\begin{array}{c}\text { above } \\
\text { average }\end{array}$ & 0.60 & high & 0.74 & $\begin{array}{l}\text { above } \\
\text { average }\end{array}$ & 0.52 \\
\hline A6 & 0.25 & 0.34 & 0.35 & 0.80 & 0.4 & 0.92 & 0.35 & 0.82 & 0.3 & 0.58 \\
\hline A7 & 72 & 0.36 & 78 & 0.80 & 75 & 0.61 & 74 & 0.56 & 75 & 0.60 \\
\hline
\end{tabular}

Table 4. Expert assessments of the significance of business process criteria

\begin{tabular}{|c|c|c|c|c|c|c|c|c|c|c|c|c|c|}
\hline \multirow[b]{2}{*}{$\begin{array}{l}\text { The } \\
\text { criteria }\end{array}$} & \multicolumn{13}{|c|}{ Expert estimates (weighting factors) } \\
\hline & $\begin{array}{c}\text { LLC } \\
\text { "Company } \\
\text { Leoprint" }\end{array}$ & $\begin{array}{c}\text { LLC } \\
\text { "Publishing } \\
\text { House" } \\
\text { Strengthening " }\end{array}$ & $\begin{array}{l}\text { LLC } \\
\text { "Grif } \\
\text { Fund" }\end{array}$ & $\begin{array}{c}\text { LLC } \\
\text { "Domain- } \\
\text { Druk" }\end{array}$ & $\begin{array}{l}\text { LLC } \\
\text { "Diz- } \\
\text { Art" }\end{array}$ & $\begin{array}{l}\text { JV LLC } \\
\text { Triada } \\
\text { Service" }\end{array}$ & $\begin{array}{l}\text { LLC } \\
\text { "Ekko" }\end{array}$ & $\begin{array}{l}\text { LLC } \\
\text { "Color } \\
\text { Sky" }\end{array}$ & $\begin{array}{c}\text { LLC } \\
\text { Chervonogradsk } \\
\text { City Printing } \\
\text { House" } \\
\end{array}$ & $\begin{array}{c}\text { LLC } \\
\text { "Sphere" }\end{array}$ & $\begin{array}{c}\text { LLC } \\
\text { "Kraplak" }\end{array}$ & $\begin{array}{c}\text { LLC } \\
\text { Etisoft- } \\
\text { Ukraine" }\end{array}$ & Average \\
\hline $\mathrm{A} 1$ & 7 & 8 & 8.5 & 8 & 8.5 & 8.5 & 7 & 8 & 8 & 8.5 & 7.5 & 8.5 & 8 \\
\hline A2 & 4 & 3 & 2 & 4 & 5 & 6 & 3 & 5 & 2 & 5 & 5 & 3 & 3.9 \\
\hline A3 & 1.4 & 3 & 2 & 1.5 & 2 & 2 & 1 & 3 & 2.5 & 2 & 3 & 1 & 2.0 \\
\hline A4 & 7.5 & 6.5 & 8 & 5.5 & 6 & 8 & 6 & 5.5 & 7 & 7.5 & 6 & 7 & 6.7 \\
\hline A5 & 4 & 4.5 & 3.8 & 6.5 & 6 & 5.5 & 4 & 4 & 6 & 5 & 5 & 6 & 5.0 \\
\hline A6 6 & 10 & 9.5 & 9 & 10 & 10 & 9.5 & 9 & 10 & 9.5 & 10 & 10 & 9.5 & 9.7 \\
\hline A7 & 7.5 & 8 & 7 & 8.5 & 7.5 & 9 & 7 & 8.5 & 8 & 8.5 & 7 & 7.5 & 7.8 \\
\hline
\end{tabular}

The priority vector of the criteria is determined based on the importance of each parameter to achieve the best efficiency of the business process for the production of engineering products in the Lviv region: the greater the value of this parameter, the greater its contribution to efficiency. First, the importance of the criteria is evaluated in numerical values from the interval $[0,10]$ (Table 4).

Further, in accordance with formula 6, we have calculated the values of the weighting coefficients (Table 5).

Table 5. Values of the weighting coefficients

\begin{tabular}{ccc}
\hline \multirow{2}{*}{ Criteria } & \multicolumn{2}{c}{ Weighting } \\
& Value & Coefficient \\
\hline A1 & 8.1 & 0.19 \\
A2 & 4.0 & 0.09 \\
A3 & 2.0 & 0.05 \\
A4 & 6.9 & 0.16 \\
A5 & 5.1 & 0.12 \\
A6 & 9.7 & 0.22 \\
A7 & 7.9 & 0.18 \\
\hline
\end{tabular}

Using formula 7 to streamline business process options for the production of engineering products by engineering enterprises of Ukraine, we have obtained the value of the membership function (Table 6).

Accordingly, we have obtained the following values for each of the options $\left(\mu_{\tilde{T}}\left(K_{1}\right)=0,54, \mu_{\tilde{T}}\left(K_{2}\right)=0,68\right.$, $\left.\mu_{\tilde{T}}\left(K_{3}\right)=0,67, \mu_{\tilde{T}}\left(K_{4}\right)=0,69, \mu_{\tilde{T}}\left(K_{5}\right)=0,68\right)$. As a result, most engineering companies consider the best and priority way to implement the business process for the production of engineering products using the fourth option. Considering the results obtained and the corresponding minor differences between the second, third, fourth and fifth options for the implementation of the business process for the production of engineering products, we can say that all these four methods will be priority, and the advantage at the choice of each of them will be given to engineering enterprises, depending on the available resources and the specific type of engineering products. An obvious outsider of our study is the business process for the production of engineering products using offset printing, which is also confirmed by global trends in reducing the share of offset in the manufacture of engineering products in the context of ensuring security.

At the final stage of our research, in our opinion, it would be advisable to form a visual display of the results. To do this, we have built a model of priority for the implementation of the business process in the context of ensuring security (Figure 1).

Table 6. Values of the weighting coefficients

\begin{tabular}{ccccccc}
\hline Criteria & Weight Ratio & Option 1 & Option 2 & Option 3 & Option 4 & Option 5 \\
\hline A1 & 0.19 & 0.75 & 0.43 & 0.24 & 0.41 & 0.83 \\
A2 & 0.09 & 0.74 & 0.83 & 0.97 & 0.70 & 0.85 \\
A3 & 0.05 & 0.41 & 0.58 & 0.63 & 0.80 & 0.66 \\
A4 & 0.16 & 0.57 & 0.59 & 0.78 & 0.93 & 0.75 \\
A5 & 0.12 & 0.69 & 0.74 & 0.60 & 0.74 & 0.52 \\
A6 & 0.22 & 0.34 & 0.80 & 0.92 & 0.82 & 0.58 \\
A7 & 0.18 & 0.36 & 0.80 & 0.61 & 0.56 & 0.60 \\
Membership Function Value & & 0.54 & 0.68 & 0.67 & 0.69 & 0.68 \\
\hline
\end{tabular}




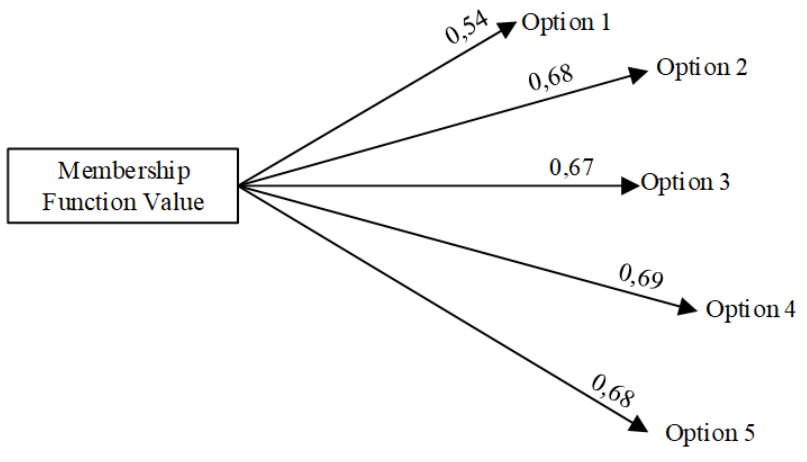

Figure 1. Model of priority for the implementation of the business process in the context of ensuring security

\section{CONCLUSIONS}

The methodology for assessing the effectiveness of the transformation of the main business processes at the enterprises, based on the theory of fuzzy sets, is a convenient means of performing multi-criteria evaluation, comparative analysis from the perspective of an integrated criterion and obtaining an ordered priority of business processes according to their effectiveness. The correspondence of the business process to each of the criteria is presented in the form of a fuzzy set, which makes this methodological approach convenient for processing and forming a multi-criteria analysis system in order to find the most optimal of the possible business processes. A model of this methodology has been analyzed based on activities of engineering enterprises in the context of ensuring security.

The approach allows us to draw the following conclusions:

- a methodological approach based on the theory of fuzzy sets is a powerful tool that allows for multi-criteria assessment and comparative analysis of the implementation of business processes by engineering enterprises, including the selection of the best option for implementing a business process for the production of engineering products;

- studies of a fuzzy set of business processes with an appropriate degree of affiliation for each of them allows us to evaluate it from the perspective of an integrated criterion and obtain an ordered priority of business processes with their overall efficiency;

- the compliance of the business process with each of the above criteria seems to be a fuzzy set, membership in which is determined by experts;

- a methodological approach is presented that is convenient for computer processing and can be used to form a multicriteria analysis system and select the most optimal of the presented business processes.

\section{REFERENCES}

[1] Schäfers, B., Zapf, W. (2001). Handwörterbuch zur Gesellschaft Deutschlands: 2. Erweiterte und aktualisierte. Bundeszentrale für politische Bildung, Bonn, pp. 145-162. ISBN: 978-3-322-94977-6.

[2] Harrington, E.C. (1965). The desirability function. Industrial Quality Control, 21(10): 494-498.

[3] Mäkeläinen, E., Roztocki, N. (1998). Economic Value Added (EVA) for small business. Retrieved March. http://www.evanomics.com/download/evaspres.pdf.

[4] Epstein, M.J., Manzoni, J.F. (1997). The balanced scorecard and tableau de bord: Translating strategy into action. Strategic Finance, 79(2): 28-36.

[5] Kaplan, R.S., Norton, D.P. (1996). The balanced scorecard: Translating strategy into action. Boston, HBS Press, 30(4): 712-736. https://doi.org/10.5465/AMR.2005.18378874

[6] Kaplan, R.S., Cooper, R. (1997). Cost and Effect: Using Integrated Cost Systems to Drive Profitability and Performance. Harvard Business School Press.

[7] Oliver, N., Delbridge, R., Barton, H. (2002). Lean production and manufacturing performance improvement in Japan, the US and UK 1994-2001. ESRC Centre for Business. http://orca.cardiff.ac.uk/id/eprint/49683.

[8] Balashova, E. (2019). Indicators for assessing the organizational effectiveness of business processes. Scientific and technical Vedas St. Petersburg. state Polytechnic un-that. Ser: Economics, (2): 185-190.

[9] Nam, D., Lee, J., Lee, H. (2019). Business analytics adoption process: An innovation diffusion perspective. International Journal of Information Management, 49: 411-423. https://doi.org/10.1016/j.ijinfomgt.2019.07.017

[10] Stark, J. (2020) Business Processes. In: Digital Transformation of Industry. Decision Engineering. Springer.

[11] Shtangret, A., Topalova, E., Polovcev, O., Chornenka, O., Musiyovskyi, A. (2021). Practical aspects of the use of antisipative management in the process of ensuring the economic security of an enterprise. Business: Theory and Practice, 22(1): 202-210. https://doi.org/10.3846/btp.2021.13556

[12] Khalina, O., Bazyliuk, V., Chornenka, O., Krasilych, I., Korzh, M. (2019). Formation of organizational support for the management of the economic security of engineering enterprises: methodical and practical aspects. Business: Theory and Practice, 20: 317-328. https://doi.org/10.3846/btp.2019.30

[13] Marrella, A., Mecella, M., Pernici, B., Plebani, P. (2019). A design-time data-centric maturity model for assessing resilience in multi-party business processes. Information Systems, $\quad 86: \quad 62-78$. https://doi.org/10.1016/j.is.2018.11.002

[14] Andreychikov, A.V., Andreychikova, O.N. (2000). Analysis, Synthesis, Planning Decisions in the Economy. Moscow: Finance and Statistics.

[15] Biznes. (2020). Oksfordskiy tolkovyy slovar. Anglorusskiy [Business: Oxford explanatory dictionary. Anglo-Russian]. Moscow: Ves mir. 